\title{
Measurement of radionuclides in surface soil and beach sand samples from Rayong Province (Thailand) and the evaluation of excess lifetime cancer risk
}

\author{
Prasong Kessaratikoon ${ }^{\mathrm{a}, *}$, Ruthairat Boonkrongcheep ${ }^{\mathrm{a}}$, Sitthipong Polthum ${ }^{\mathrm{b}}$ \\ a Nuclear and Material Physics Research Unit, Department of Basic Science and Mathematics, Faculty of \\ Science, Thaksin University, Songkhla 90000 Thailand \\ b Thailand Institute of Nuclear Technology (Public Organization), Ongkharak, Nakhon Nayok 26120 \\ Thailand
}

*Corresponding author, e-mail: prasong_mi@hotmail.com

Received 11 Nov 2020

Accepted 18 Jun 2021

\begin{abstract}
Specific activities of natural $\left({ }^{40} \mathrm{~K},{ }^{226} \mathrm{Ra}\right.$, and $\left.{ }^{232} \mathrm{Th}\right)$ and anthropogenic $\left({ }^{137} \mathrm{Cs}\right)$ radionuclides in 230 surface soil and beach sand samples collected from the densely populated areas of industrial activities in Rayong Province, Thailand, were analyzed. Experimental results were obtained using a high-purity germanium detector and gamma spectrometric analysis system. The frequency distributions of the four radionuclides were investigated and calculated as suitable medium values of all distributions. According to asymmetrical distribution, medium values of the specific activities of all required radionuclides should be median values. Furthermore, the median values of the three natural radionuclides were also used to evaluate absorbed dose rates in the air (D), radium equivalent $\left(\mathrm{Ra}_{\mathrm{eq}}\right)$, external hazard index $\left(\mathrm{H}_{\mathrm{ex}}\right)$, annual effective dose rate $\left(\mathrm{AED}_{\text {out }}\right)$, and excess lifetime cancer risk (ELCR) in the studied areas. The results were compared with data obtained from the annual report of Thailand's Office of Atoms for Peace, the global radioactivity measurements, and the evaluations and recommended values proposed by the United Nations Scientific Committee on the Effects of Atomic Radiation (UNSCEAR). It was found that most of the results were significantly lower than the recommended values of UNSCEAR except for the median value of specific activity of ${ }^{226}$ Ra. Moreover, the radioactive contour map for the investigated areas was constructed.
\end{abstract}

KEYWORDS: radionuclides, high-purity germanium detector, gamma-ray spectrometry, radiological hazard index, excess lifetime cancer risk

\section{INTRODUCTION}

Rayong Province, located in Eastern Thailand, has played an important role as part of the Eastern Seaboard Development Project since 1982. It is a gateway for the Northeast region to send products to foreign countries without passing through Bangkok. The Thai government has prepared a complete basic utility system and designated Map Ta Phut, Mueang District, Rayong Province as a location of the industrial estate. The primary industries in Rayong Province are natural gas separation plants, petrochemical industry, and chemical fertilizer industry. Hence, the province comprises industrial estates jointly operated with many private individuals, industrial areas, industrial communities, and industrial parks, thus having a high potential for industrial investment and rapid industrial development $[1,2]$. It creates a total annual value of almost one-third of Thailand's Gross Domestic
Product (GDP). Moreover, Rayong Province has been recently selected as one of the three provinces, besides Chonburi and Chachoengsao, promoted for industrial progress in the Eastern Economic Corridor (EEC) Project. As a result, Rayong Province is an area of continuous industrial development, and a significant increase in number of factories in parallel with an increase in accidents in this area is foreseen.

There are seven refineries for crude oil refining industry in Thailand. Almost all are located in the eastern part of the country. Oil refinery is classified as one of fourteen types of high-polluting plants according to the Notification of the Ministry of Industry in the year 2002 [3]. Although oil refining provides enormous benefits to humans, it also causes many environmental pollutants and, in particular, an increase or build-up of radioactive materials in the environment. The existence of radioactive materials coincides with the creation of the Earth. Therefore, rocks and sand on the Earth's 
surface and crude oil, caused by the deposition of fossil in the shale beneath the Earth's surface for millions years, are composed of radioactive substances $[4,5]$. Measuring the amount of radioactivity in the area where the manufacturing industry is located has been a point of interest worldwide, especially to monitor the concentration of natural and artificial radionuclides in the environment [6-10]. In the United States, State and Federal regulatory agencies have developed guidelines for controlling naturally occurring radioactive materials that will adequately protect health of the public and the environment [11]. The European Union (EU) has also focused on the survey and measurement of radioactive substances from oil and gas productions among the the EU member states [12]. In addition, the Safety Report Series 34 of the International Atomic Energy Agency (IAEA) also provides information on the naturally occurring radioactive substances in oil and gas productions [13].

Generally, the geology of Rayong Province is not quite intricate. Two principal rock types, namely sedimentary rocks and igneous rocks, are found in the area. Granitic rock, which is one type of igneous rock mainly Triassic in age, underlines approximately $20 \%$ of the area. Hence, some natural radionuclides such as ${ }^{226} \mathrm{Ra},{ }^{232} \mathrm{Th}$, and ${ }^{40} \mathrm{~K}$ might be accumulated in this area. The distribution of these radionuclides has proved to be important in estimating the level of natural background radiation to which humans are exposed [14].

For this reason, we were interested in the measurement and analysis of background radioactivity of Rayong Province. The aim was to measure and analyze specific activities of natural radioactive nuclides $\left({ }^{226} \mathrm{Ra},{ }^{232} \mathrm{Th}\right.$, and $\left.{ }^{40} \mathrm{~K}\right)$ and man-made radioactive nuclides $\left({ }^{137} \mathrm{Cs}\right)$ in surface soil and beach sand samples collected from eight districts in Rayong Province. The frequency distribution and some medium values of all measured specific activities were investigated. Then, some interesting radiological hazard indices and ELCR value were also evaluated using the suitable medium values from the frequency distribution values. Moreover, the radioactive contour maps (RCM) of all radioactive nuclides were created.

\section{MATERIALS AND METHODS}

\section{Studied areas}

Rayong Province, one of the seven provinces in Eastern Thailand, is located at $12^{\circ} 40^{\prime} 51.4^{\prime \prime} \mathrm{N}$ latitude and $101^{\circ} 15^{\prime} 28.7^{\prime \prime}$ E longitude (Fig. 1) with neighboring Chonburi Province to the north-west, Chanthaburi Province to the north-east, and the Gulf of Thailand to the south. The province is divided into eight districts: Mueang, Ban Chang, Nikhom Phatthana, Pluak Daeng, Ban Khai, Wang Chan, Khao Chamao, and Klaeng Districts. The population of Rayong Province was 723,316 in 2018.

\section{Surface soil and beach sand sample collection and preparation}

Two hundred surface soil samples (yellow color) were collected from populated areas in the eight districts (Fig. 1). At the same time, 30 beach sand samples (blue color) were collected from Mae Ram Phueng Beach located in the south of Mueang District of the studied area. The collected surface soil samples were ground and homogenized and airdried for several days. In the meantime, the beach sand samples were taken to dry in the ambient environment for 2-3 days. Both the surface soil and the beach sand samples were placed in an oven at $100^{\circ} \mathrm{C}$ for at least $3 \mathrm{~h}$ to eliminate any traces of water and, then, were sieved through a $2 \mathrm{~mm}$ mesh-sized. Approximately $420 \mathrm{~g}$ of each meshed surface soil and beach sand sample was removed to a PVC $(8.2 \mathrm{~cm} \times 7.5 \mathrm{~cm})$ cylindrical container. The container was sealed hermetically and externally using cellophane tape and left for about four weeks to ensure equilibrium between ${ }^{226} \mathrm{Ra}$ and its daughters and ${ }^{228} \mathrm{Ra}$ and its daughters [15].

\section{Measurement, analysis, and frequency distribution of specific activities}

The specific activities of natural $\left({ }^{226} \mathrm{Ra},{ }^{232} \mathrm{Th}\right.$, and $\left.{ }^{40} \mathrm{~K}\right)$ and anthropogenic $\left({ }^{137} \mathrm{Cs}\right)$ radionuclides in 230 surface soil and beach sand samples were determined using a high-purity germanium detector (HPGe, EG\&G ORTEC Model GEM 20 P4) and gamma spectrometric analysis system at the Thailand Institute of Nuclear Technology (Public Organization) (TINT). The detector was enclosed in a massive $10-\mathrm{cm}$ thick lead shielding. The container's geometric efficiency for soil matrices was determined by the IAEA Soil-375 reference materials (International Atomic Energy Agency IAEA, Vienna, Austria). Gamma-ray energies of ${ }^{214} \mathrm{~Pb}$ $(351.9 \mathrm{keV}),{ }^{214} \mathrm{Bi}(609.3,1764.5 \mathrm{keV})$, and ${ }^{226} \mathrm{Ra}$ $(185.99 \mathrm{keV})$ were used to estimate the specific activities of ${ }^{226} \mathrm{Ra}$ [16]. Evaluation of specific activities of ${ }^{232} \mathrm{Th}$ was from gamma-lines of ${ }^{212} \mathrm{~Pb}$ (238.6 keV) and ${ }^{228} \mathrm{Ac}(338.4,911.07,968.90 \mathrm{keV})$. The specific activities of ${ }^{40} \mathrm{~K}$ and ${ }^{137} \mathrm{Cs}$ in all samples were evaluated from gamma energies 1460.8 and 


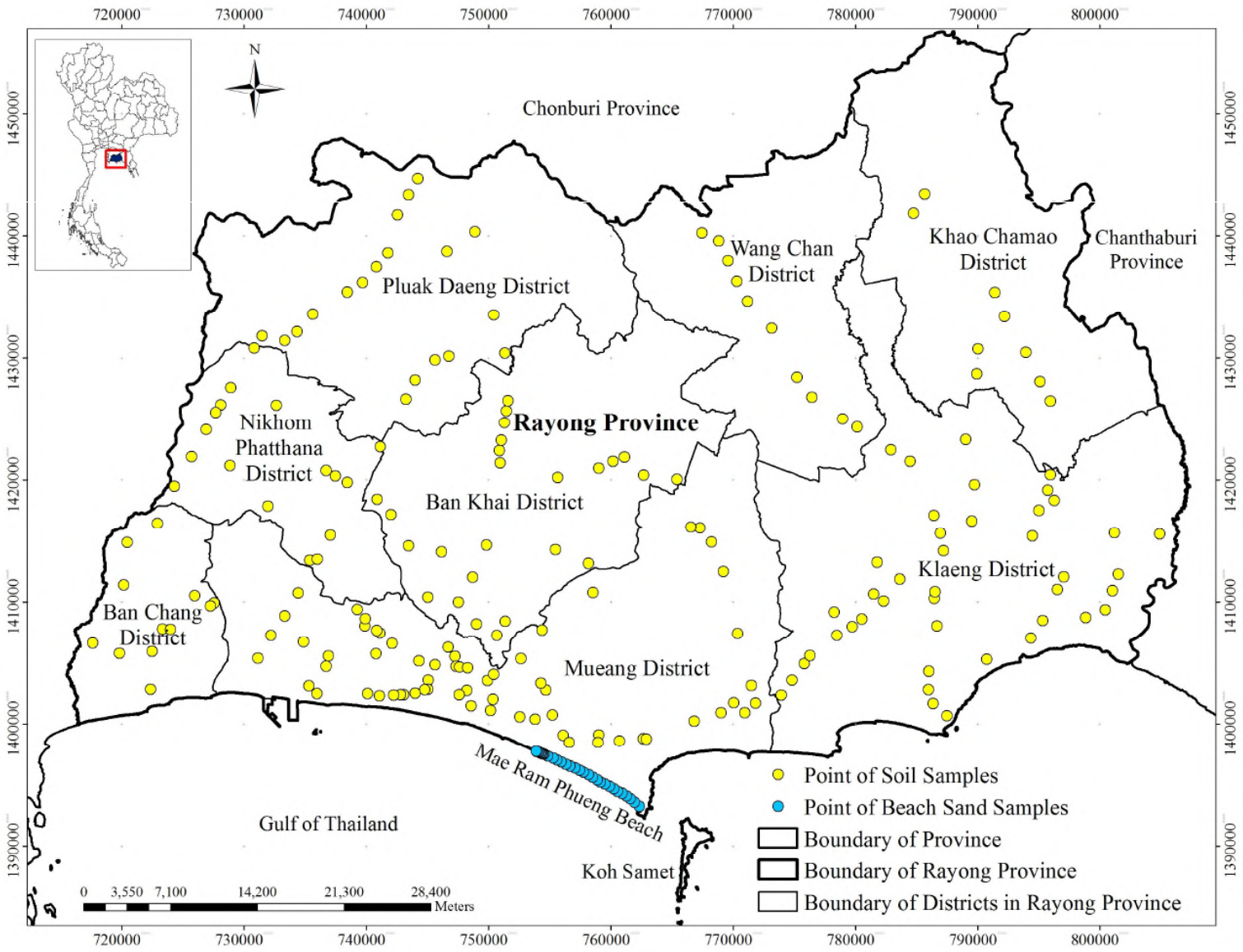

Fig. 1 Geographical map of Rayong Province and sampling locations.

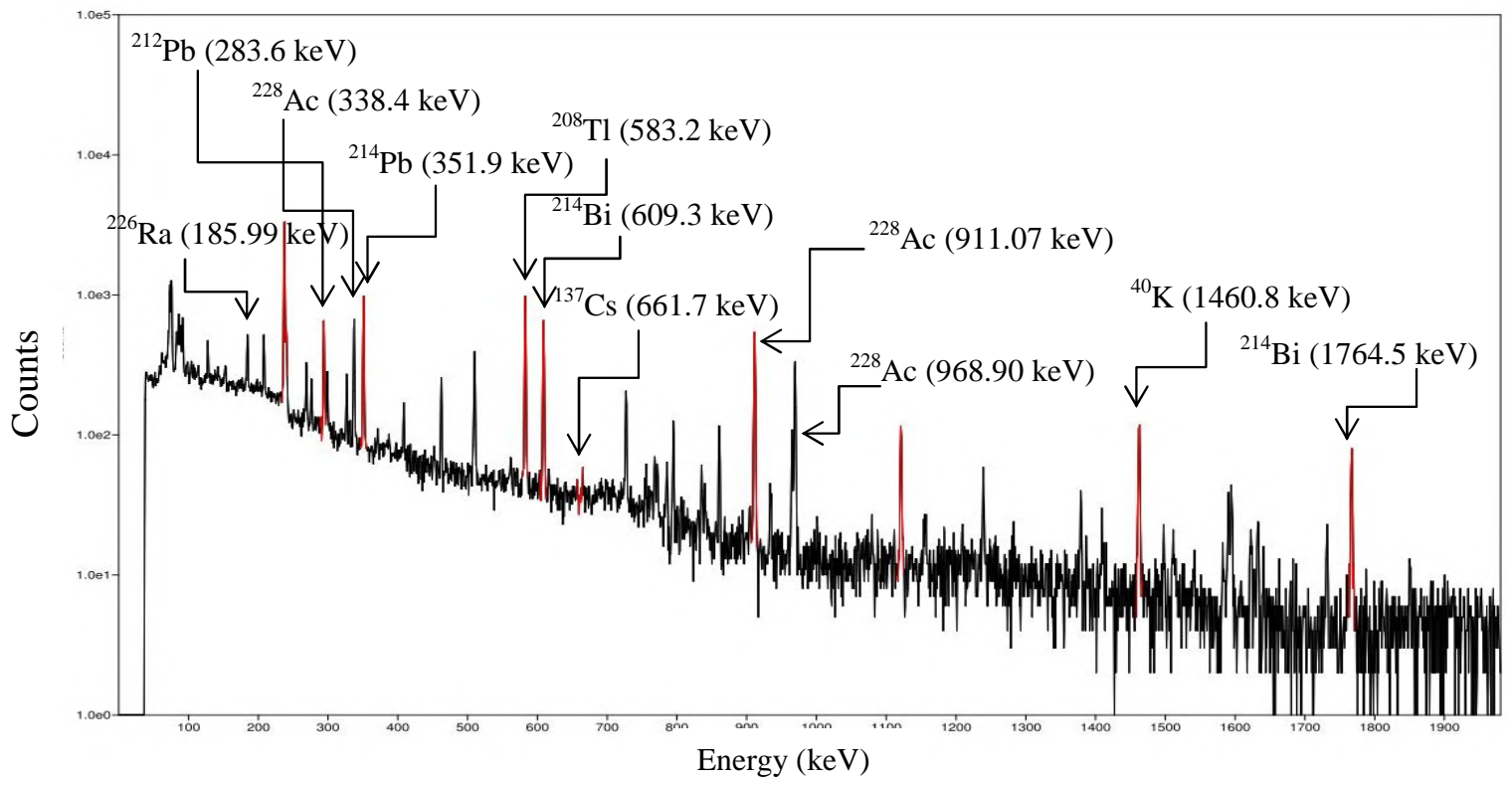

Fig. 2 The gamma-ray energy spectrum of surface soil sample collected from Klang District, Rayong Province. 
$661.7 \mathrm{keV}$ of themselves, respectively (Fig. 2). The SPSS computer program was employed to analyze the frequency distribution of specific activities of ${ }^{226} \mathrm{Ra},{ }^{232} \mathrm{Th},{ }^{40} \mathrm{~K}$, and ${ }^{137} \mathrm{Cs}$ radionuclides. The results were compared with existing data in Thailand and global measurement and evaluation.

\section{Evaluation of radiological hazard indices and excess lifetime cancer risk}

The specific activities of the four radionuclides in the surface soil and beach sand samples [16] were evaluated from Eq. (1):

$$
\text { S.A. }=\frac{\mathrm{C}}{\epsilon \times \mathrm{P} \times \mathrm{m} \times \mathrm{t}},
$$

where S.A. = specific activity of a radionuclide $(\mathrm{Bq} / \mathrm{kg}) ; \mathrm{C}=$ count rate under related full energy peak; $\epsilon=$ detection efficiency at energy $\mathrm{E}$; $\mathrm{P}=$ abundance of the gamma line in a radionuclide; $\mathrm{m}=$ soil sample mass $(\mathrm{kg})$; and $\mathrm{t}=$ counting time. The minimum detectable activity (MDA) of each radionuclide was also evaluated at the 95\% confidence level. The average values of MDA for ${ }^{226} \mathrm{Ra},{ }^{232} \mathrm{Th},{ }^{40} \mathrm{~K}$, and ${ }^{137} \mathrm{Cs}$ were $8.11,3.77,63.43$, and $0.82 \mathrm{~Bq} / \mathrm{kg}$, respectively, for a counting time of $10800 \mathrm{~s}$ and approximately $420 \mathrm{~g}$ of the surface soil and the beach sand samples.

By using the conversion factors published [17] and with all selected medium values of specific activity of ${ }^{226} \mathrm{Ra},{ }^{232} \mathrm{Th}$, and ${ }^{40} \mathrm{~K}$ from this study, the absorbed dose rate $(D)$ in outdoor air at $1 \mathrm{~m}$ above the ground could be calculated by Eq. (2):

$$
\mathrm{D}=0.461 \mathrm{C}_{\mathrm{Ra}}+0.623 \mathrm{C}_{\mathrm{Th}}+0.0414 \mathrm{C}_{\mathrm{K}} \text {, }
$$

where $\mathrm{C}_{\mathrm{Ra}}, \mathrm{C}_{\mathrm{Th}}$, and $\mathrm{C}_{\mathrm{K}}$ are suitable medium values of specific activities of ${ }^{226} \mathrm{Ra},{ }^{232} \mathrm{Th}$, and ${ }^{40} \mathrm{~K}$ in $\mathrm{Bq} / \mathrm{kg}$, respectively. Then, the radium equivalent activity $\left(\mathrm{Ra}_{\mathrm{eq}}\right)[18,19]$ could be calculated by Eq. (3):

$$
\mathrm{Ra}_{\mathrm{eq}}=\mathrm{C}_{\mathrm{Ra}}+1.43 \mathrm{C}_{\mathrm{Th}}+0.077 \mathrm{C}_{\mathrm{K}}
$$

The external hazard index $\left(\mathrm{H}_{\mathrm{ex}}\right)$ [20] was also evaluated by Eq. (4):

$$
\mathrm{H}_{\mathrm{ex}}=\mathrm{C}_{\mathrm{Ra}} / 370+\mathrm{C}_{\mathrm{Th}} / 259+\mathrm{C}_{\mathrm{K}} / 4810 \leqslant 1 .
$$

By adoption of a conversion factor of $0.7 \mathrm{~Sv} / \mathrm{Gy}$, the calculated $\mathrm{D}(\mathrm{nGy} / \mathrm{h})$ value in outdoor air was converted to the effective dose received by adults, and by consideration that people in Thailand, on the average, spend approximately $20 \%$ of their time outdoors, the annual $(8760 \mathrm{~h})$ effective dose rate
$\left(\mathrm{AED}_{\text {out }}(\mathrm{mSv} / \mathrm{y})\right)$ [17] could be determined by Eq. (5):

$$
\mathrm{AED}_{\text {out }}=\mathrm{D} \times 8760 \times 0.2 \times 0.7 \times 10^{-6} .
$$

Then the excess lifetime cancer risk (ELCR) (outdoor) [21] was also evaluated for the investigated area as shown in Eq. (6):

$$
\text { ELCR (outdoor) }=\mathrm{AED}_{\text {out }} \times \mathrm{LF} \times \mathrm{RF}
$$

where LF and RF are the life expectancy of Thai people (75 years) [22] and risk factor $\left(0.05 \mathrm{~Sv}^{-1}\right)$, respectively. All four radiological hazard indices and the ELCR (outdoor) values were calculated and compared with national and international studies, Office of Atoms for Peace (OAP) data, and the recommended values reported by the UNSCEAR $[18,23,24]$.

\section{Construction of radioactive contour maps}

The radioactive contour maps (RCM) of specific activities of ${ }^{226} \mathrm{Ra},{ }^{232} \mathrm{Th},{ }^{40} \mathrm{~K}$, and ${ }^{137} \mathrm{Cs}$ radionuclides from 230 surface soil and beach sand samples could be created and presented using the ArcGIS computer program.

\section{RESULTS AND DISCUSSION}

\section{Gamma-ray energy spectrum}

The gamma-ray energy spectrum of surface soil and beach sand samples in Rayong Province showed the existence of natural $\left({ }^{226} \mathrm{Ra},{ }^{232} \mathrm{Th}\right.$, and $\left.{ }^{40} \mathrm{~K}\right)$ and anthropogenic $\left({ }^{137} \mathrm{Cs}\right)$ radionuclides (Fig. 2). To estimate the terrestrial gamma dose rate for outdoor occupation, it is very important to evaluate the specific activities of natural radionuclides in soils. Since $98.5 \%$ of the radiological effects of the uranium series are produced by radium and its daughter products, the natural radioactivity of soil samples is usually determined from the ${ }^{226} \mathrm{Ra}$, ${ }^{232} \mathrm{Th}$ and ${ }^{40} \mathrm{~K}$ contents. Not only these three natural radionuclides, but also anthropogenic radionuclide $\left({ }^{137} \mathrm{Cs}\right)$ may become air-borne, and inhalation of contaminated dust can result in an internal exposure $[16,17,24]$.

\section{Frequency distribution of specific activities and statistic values}

The frequency distribution of calculated specific activities of ${ }^{226} \mathrm{Ra},{ }^{232} \mathrm{Th},{ }^{40} \mathrm{~K}$, and ${ }^{137} \mathrm{Cs}$ in 230 surface soil and beach sand samples is shown in Fig. 3 . Some important statistic values were calculated, and the results are shown in Table 1. 


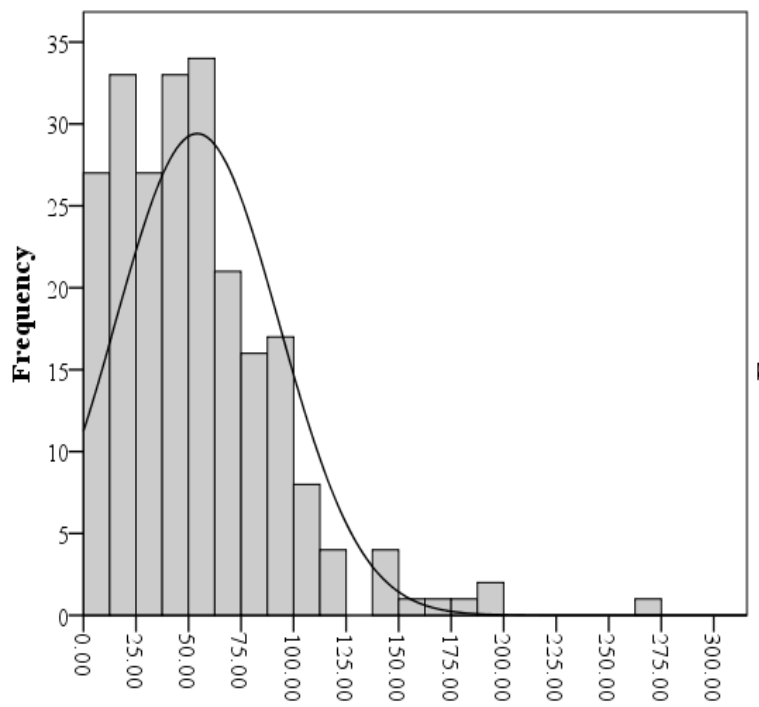

Specific Actitvity of Ra-226 in Rayong Province $(\mathrm{Bq} / \mathrm{kg})$

(a)

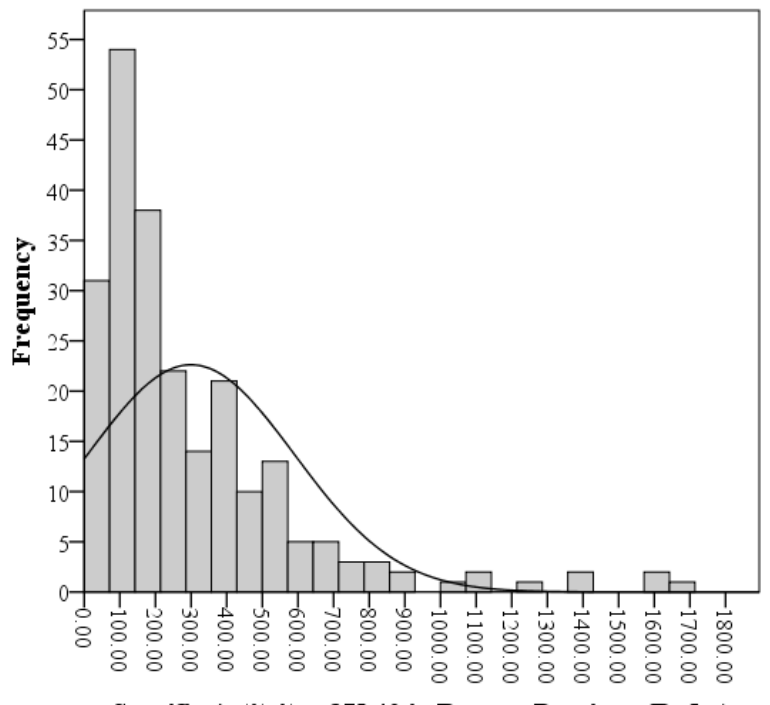

Specific Actitvity of K-40 in Rayong Province $(\mathrm{Bq} / \mathrm{kg})$

(c)

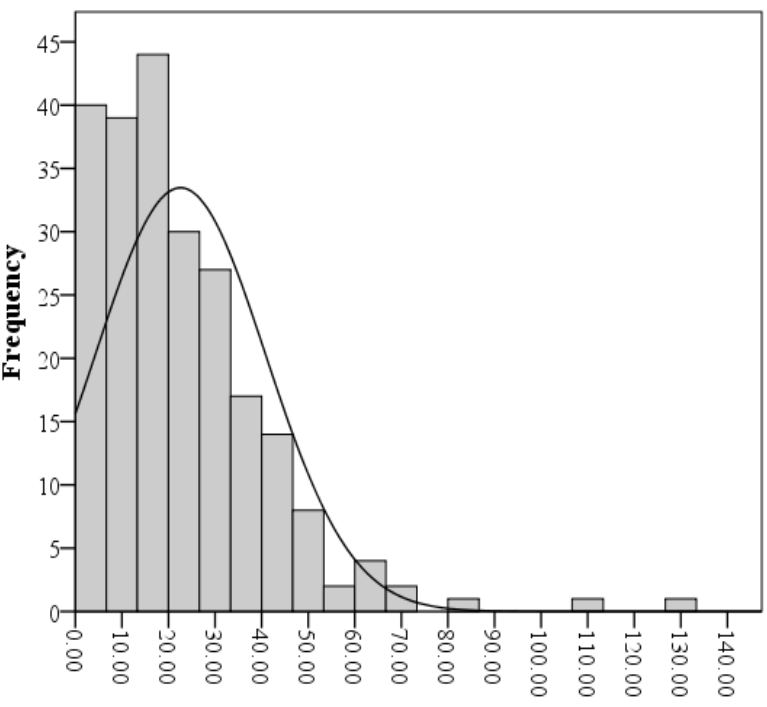

Specific Actitvity of Th-232 in Rayong Province $(\mathrm{Bq} / \mathrm{kg})$

(b)

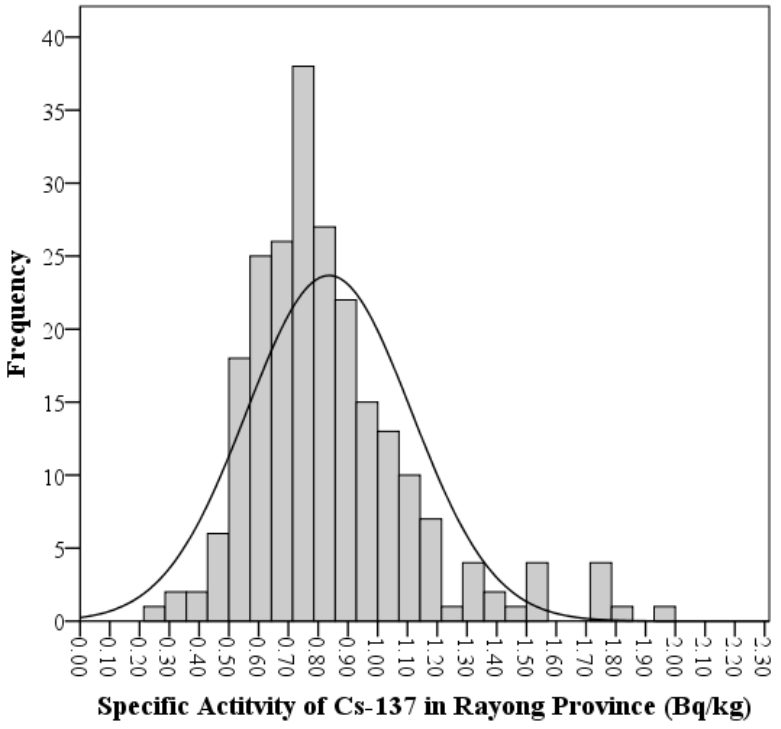

(d)

Fig. 3 Frequency distribution of specific activities of: (a) ${ }^{226} \mathrm{Ra}$; (b) ${ }^{232} \mathrm{Th}$; (c) ${ }^{40} \mathrm{~K}$, and (d) ${ }^{137} \mathrm{Cs}$ in 230 surface soil and beach sand samples collected from Rayong Province.

From Fig. 3 and Table 1, it was found that the frequency distribution of specific activities of ${ }^{226} \mathrm{Ra}$, ${ }^{232} \mathrm{Th},{ }^{40} \mathrm{~K}$, and ${ }^{137} \mathrm{Cs}$ in 230 surface soil and beach soil samples collected from Rayong Province were not symmetrical, with the skewness of 1.57, 1.95, 2.23 , and 1.36, respectively. All the distributions were positive skewness or right-skewness of the data set indicating the asymmetric distributions in nature. In addition, these radionuclides showed a normal (bell-shaped) distribution, especially the
${ }^{137} \mathrm{Cs}$. Furthermore, ${ }^{226} \mathrm{Ra},{ }^{232} \mathrm{Th}$, and ${ }^{40} \mathrm{~K}$ presented some degree of multi-modality [25] exhibiting the complexity of minerals in soil surface and beach sand samples. It also contributed to the emission of gamma radiation in the investigated area. The median values of ${ }^{226} \mathrm{Ra},{ }^{232} \mathrm{Th},{ }^{40} \mathrm{~K}$, and ${ }^{137} \mathrm{Cs}$ were 47.28 $\pm 1.39,18.46 \pm 0.70,209.03 \pm 8.01$, and $<0.78 \mathrm{~Bq} / \mathrm{kg}$, respectively. Consequently, four radiological hazard indices and ELCR (outdoor) could be evaluated using this study's representative 
Table 1 Statistic values of the frequency distribution of specific activities of natural $\left({ }^{226} \mathrm{Ra},{ }^{232} \mathrm{Th}\right.$, and $\left.{ }^{40} \mathrm{~K}\right)$ and anthropogenic $\left({ }^{137} \mathrm{Cs}\right)$ radionuclides in 230 surface soil and beach sand samples collected from the studied areas.

\begin{tabular}{lccrr}
\hline \multirow{2}{*}{ Statistic value } & \multicolumn{4}{c}{ Analyzed value } \\
\cline { 2 - 5 } & ${ }^{226} \mathrm{Ra}$ & ${ }^{232} \mathrm{Th}$ & ${ }^{40} \mathrm{~K}$ & $<0.84$ \\
\hline Mean $(\mathrm{Bq} / \mathrm{kg})$ & $54.09 \pm 1.40$ & $22.57 \pm 0.70$ & $299.07 \pm 8.22$ & $<0.78$ \\
Median (Bq/kg) & $47.28 \pm 1.39$ & $18.46 \pm 0.70$ & $209.03 \pm 8.01$ & $<0.57$ \\
Mode $(\mathrm{Bq} / \mathrm{kg})$ & 10.55 & 5.16 & 340.81 & 1.36 \\
Skewness & 1.57 & 1.95 & 2.23 & 2.61 \\
Kurtosis & 4.35 & 6.70 & 6.14 & $<0.26$ \\
Minimum value $(\mathrm{Bq} / \mathrm{kg})$ & 7.25 & 1.44 & 21.30 & $<1.95$ \\
Maximum value $(\mathrm{Bq} / \mathrm{kg})$ & 265.58 & 129.26 & 1654.53 & \\
\hline
\end{tabular}

Table 2 The values of specific activities of natural $\left({ }^{226} \mathrm{Ra},{ }^{232} \mathrm{Th}\right.$, and $\left.{ }^{40} \mathrm{~K}\right)$ and anthropogenic $\left({ }^{137} \mathrm{Cs}\right)$ radionuclides in 12 provinces in Southern Thailand, OAP annual report data, and enlisted worldwide mean compared with the present study.

\begin{tabular}{lcccc}
\hline \multirow{2}{*}{ Location } & \multicolumn{3}{c}{ Specific Activity (Bq/kg) } \\
\cline { 2 - 5 } & ${ }^{226} \mathrm{Ra}$ & ${ }^{232} \mathrm{Th}$ & ${ }^{40} \mathrm{~K}$ & \multicolumn{1}{c}{${ }^{137} \mathrm{Cs}$} \\
\hline Rayong $^{\mathrm{a}}$ & $47.28 \pm 1.39$ & $18.46 \pm 0.70$ & $209.03 \pm 8.01$ & $<.78$ \\
Songkhla P. [26] & $107.28 \pm 6.74$ & $51.53 \pm 5.02$ & $3562.14 \pm 223.56$ & $3.05 \pm 1.58$ \\
Nakhon Si Thammarat P. [27] & $108.55 \pm 31.19$ & $73.95 \pm 4.15$ & $4313.18 \pm 148.16$ & $4.84 \pm 2.59$ \\
Phatthalung P. [28] & $135.89 \pm 6.71$ & $76.34 \pm 5.32$ & $3573.35 \pm 203.89$ & $4.00 \pm 1.92$ \\
Chumphon P. [29] & $57.32 \pm 5.19$ & $56.98 \pm 4.68$ & $2135.69 \pm 168.87$ & $2.30 \pm 1.38$ \\
Surat Thani P. [30] & $75.72 \pm 5.75$ & $47.77 \pm 4.79$ & $2119.10 \pm 171.72$ & $3.85 \pm 1.67$ \\
Ranong P. [31] & $71.39 \pm 1.66$ & $38.11 \pm 1.09$ & $470.80 \pm 14.56$ & N.A. \\
Trang P. [32] & $69.86 \pm 3.26$ & $79.22 \pm 4.36$ & $382.75 \pm 23.45$ & $1.72 \pm 0.83$ \\
Satun P. [33] & $102.54 \pm 7.05$ & $124.46 \pm 4.52$ & $4146.73 \pm 251.13$ & $5.30 \pm 2.30$ \\
Yala P. [34] & $128.94 \pm 7.42$ & $85.93 \pm 6.13$ & $3607.70 \pm 235.48$ & $4.53 \pm 2.24$ \\
Phuket P. [35] & $240.11 \pm 10.79$ & $210.68 \pm 9.89$ & $4896.45 \pm 288.74$ & $5.91 \pm 2.94$ \\
Phang-Nga P. [35] & $165.44 \pm 8.44$ & $160.11 \pm 7.92$ & $2879.87 \pm 225.50$ & $5.76 \pm 2.49$ \\
Krabi P. [35] & $65.75 \pm 4.95$ & $40.69 \pm 3.96$ & $802.58 \pm 115.25$ & $2.96 \pm 1.59$ \\
South Africa [36] & 271.96 & 47.65 & 87.17 & N.A. \\
Nigeria [37] & 42.95 & 26.84 & 111.05 & 3.56 \\
Saudi Arabia [38] & 16.73 & 10.40 & 419.78 & N.A. \\
India [39] & $30.24 \pm 0.53$ & $29.89 \pm 0.61$ & $291.06 \pm 0.57$ & N.A. \\
China [40] & $23.25 \pm 9.40$ & $26.90 \pm 10.22$ & $133.84 \pm 42.87$ & N.A. \\
OAP (Southern region of Thailand [41] & $171.55 \pm 3.13$ & $211.19 \pm 1.98$ & $511.04 \pm 7.04$ & $1.13 \pm 0.49$ \\
Worldwide mean [18] & 35 & 30 & 400 & N.A. \\
\hline
\end{tabular}

${ }^{\text {a }}$ Present study; $\mathrm{P}=$ Province; N.A. = Not available.

median values as follows.

The median values of specific activities of all four radionuclides in 230 surface soil and beach sand samples in the investigated area were used to compare with the Office of Atoms for Peace (OAP) annual report data, some Thailand and global radioactivity measurements and evaluations as shown in Table 2 [18, 26-41].

From the result in Table 2 , the median value of specific activity of ${ }^{226} \mathrm{Ra}$ of the present study was higher than the values of Nigeria, Saudi Arabia, India, China, and the worldwide mean. For
${ }^{232} \mathrm{Th}$, the median value of Rayong Province was only higher than the Saudi Arabia's, while the value for ${ }^{40} \mathrm{~K}$ was higher than the South Africa, Nigeria, and China data. However, the median value of specific activities of ${ }^{137} \mathrm{Cs}$ was the lowest compared with all locations. It should be noticed that the obtained median value of specific activities of ${ }^{226} \mathrm{Ra}$, which might be directly caused by the oil and gas industries [42], was comparable and close to the values of Chumphon, Trang, and Krabi Provinces in Thailand and Nigeria but was about 1.35 times higher than the worldwide mean value. 
Table 3 Comparison of the values obtained for Rayong Province to the national and international studies and evaluations, OAP data, and UNSCEAR recommended values.

\begin{tabular}{lccccc}
\hline Location & $\begin{array}{c}\mathrm{D} \\
(\mathrm{nGy} / \mathrm{h})\end{array}$ & $\begin{array}{c}\mathrm{Ra}_{\mathrm{eq}} \\
(\mathrm{Bq} / \mathrm{kg})\end{array}$ & $\mathrm{H}_{\mathrm{ex}}$ & $\begin{array}{c}\mathrm{AED}_{\text {out }} \\
(\mathrm{mSv} / \mathrm{y})\end{array}$ & $\begin{array}{c}\text { ELCR (outdoor) } \\
\left(\times 10^{-3}\right)\end{array}$ \\
\hline Rayong & $41.95 \pm 1.41$ & $89.77 \pm 3.00$ & $0.24 \pm 0.01$ & $0.05 \pm 0.01$ & $0.19 \pm 0.01$ \\
Songkhla P. & $229.03 \pm 15.49$ & $455.25 \pm 31.13$ & $1.23 \pm 0.08$ & $0.28 \pm 0.02$ & $1.05 \pm 0.07$ \\
Nakhon Si Thammarat P. & $274.68 \pm 23.10$ & $546.41 \pm 48.53$ & $1.48 \pm 0.13$ & $0.34 \pm 0.03$ & $1.26 \pm 0.11$ \\
Phatthalung P. & $258.14 \pm 14.85$ & $520.20 \pm 30.02$ & $1.40 \pm 0.08$ & $0.32 \pm 0.02$ & $1.19 \pm 0.07$ \\
Chumphon P. & $150.63 \pm 12.32$ & $303.91 \pm 24.93$ & $0.82 \pm 0.07$ & $0.18 \pm 0.02$ & $0.69 \pm 0.06$ \\
Surat Thani P. & $152.90 \pm 12.81$ & $308.44 \pm 25.97$ & $0.83 \pm 0.07$ & $0.19 \pm 0.02$ & $0.70 \pm 0.06$ \\
Ranong P. & $76.14 \pm 2.05$ & $162.14 \pm 4.34$ & $0.44 \pm 0.01$ & $0.09 \pm 0.01$ & $0.35 \pm 0.01$ \\
Trang P. & $202.96 \pm 11.35$ & $420.26 \pm 22.89$ & $1.13 \pm 0.06$ & $0.25 \pm 0.01$ & $0.93 \pm 0.05$ \\
Satun P. & $296.48 \pm 16.46$ & $599.82 \pm 32.85$ & $1.62 \pm 0.09$ & $0.36 \pm 0.02$ & $1.36 \pm 0.08$ \\
Yala P. & $262.33 \pm 16.99$ & $529.61 \pm 34.32$ & $1.43 \pm 0.09$ & $0.32 \pm 0.02$ & $1.21 \pm 0.08$ \\
Phuket P. & $446.92 \pm 23.19$ & $922.99 \pm 47.37$ & $2.49 \pm 0.13$ & $0.55 \pm 0.03$ & $2.06 \pm 0.11$ \\
Phang-Nga P. & $295.24 \pm 18.16$ & $616.14 \pm 37.13$ & $1.66 \pm 0.10$ & $0.36 \pm 0.02$ & $1.36 \pm 0.08$ \\
Krabi P. & $89.16 \pm 9.53$ & $186.35 \pm 19.50$ & $0.50 \pm 0.05$ & $0.11 \pm 0.01$ & $0.41 \pm 0.04$ \\
South Africa & 163.17 & $\mathrm{~N} . \mathrm{A}$. & $\mathrm{N} . \mathrm{A}$. & 0.19 & 0.66 \\
Nigeria & 40.69 & 89.49 & 0.23 & 0.05 & 0.17 \\
Saudi Arabia & 31.68 & 63.93 & 0.17 & 0.04 & 0.14 \\
India & 44.16 & 93.41 & 0.24 & 0.05 & $\mathrm{~N} . \mathrm{A}$. \\
China & $33.02 \pm 12.48$ & $72.02 \pm 27.32$ & $0.19 \pm 0.07$ & $0.04 \pm 0.02$ & $0.15 \pm 0.06$ \\
OAP Data & $231.81 \pm 2.97$ & $512.90 \pm 6.50$ & $1.39 \pm 0.02$ & $0.28 \pm 0.01$ & $1.07 \pm 0.01$ \\
UNSCEAR [18, 23, 24] & 55 & 370 & 1 & 0.48 & 1.80 \\
\hline
\end{tabular}

${ }^{\text {a }}$ Present study; $\mathrm{P}=$ Province; N.A. = Not available.

\section{Radiological hazard indices and excess lifetime cancer risk evaluation}

Using Eqs. (2)-(6) and the median values of specific activities of ${ }^{226} \mathrm{Ra},{ }^{232} \mathrm{Th}$, and ${ }^{40} \mathrm{~K}$ in Tables 1 and 2 , some radiological hazard indices, including the D, $\mathrm{Ra}_{\mathrm{eq}}, \mathrm{H}_{\mathrm{ex}}, \mathrm{AED}_{\text {out }}$, and ELCR (outdoor) could be calculated for Rayong Province. All these values were compared with national and international studies and evaluations, OAP data, UNSCEAR recommended values (Table 3 ).

From Table 3, all calculated values of four radiological hazard indices and the ELCR (outdoor) in the investigated areas were lower than the national studies but comparable with the recent international measurements and studies. All values of the investigated area were lower than the OAP data and UNSCEAR recommended values. In addition, the obtained $\mathrm{AED}_{\text {out }}$ value was about 1.71 times lower than the UNSCEAR recommended values. For this reason, the ELCR (outdoor) was evaluated and found to be about 1.68 times lower than the UNSCEAR recommended values as well. Therefore, it can be said that Rayong Province should be a harmless place from background natural radioactivity and has no jeopardy to people or tourists who come to visit and spend time in the area.
The radioactive contour maps (RCM) of the investigated area

The radioactive contour maps (RCM) of ${ }^{226} \mathrm{Ra}$, ${ }^{232} \mathrm{Th},{ }^{40} \mathrm{~K}$, and ${ }^{137} \mathrm{Cs}$ radionuclides in 230 surface soil and beach sand samples collected from Rayong Province were created by the ArcGIS computer program (Fig. 4).

The comparison of the maximum values of ${ }^{226} \mathrm{Ra},{ }^{232} \mathrm{Th}$, and ${ }^{40} \mathrm{~K}$ from Eq. (4), which were 370,259 , and $4810 \mathrm{~Bq} / \mathrm{kg}$, respectively, and the maximum value of ${ }^{137} \mathrm{Cs}(5.91 \mathrm{~Bq} / \mathrm{kg})$ from Table 2 gave the RCM of the four radionuclides for the investigated area as shown in Fig. 4. The data were created and appeared in green or light green color for the average level with not much different from the background radiation.

\section{CONCLUSION}

In this study, three main results were used to consider level of radioactive contaminants and hazardous index in Rayong Province, i.e., the median values of specific activity of natural $\left({ }^{226} \mathrm{Ra},{ }^{232} \mathrm{Th}\right.$, and $\left.{ }^{40} \mathrm{~K}\right)$ and anthropogenic $\left({ }^{137} \mathrm{Cs}\right)$ radionuclides in the surface soil and beach sand samples, the four radiological hazard indices ( $D, \mathrm{Ra}_{\mathrm{eq}}, \mathrm{H}_{\mathrm{ex}}$, and $\mathrm{AED}_{\text {out }}$ ) and the ELCR (outdoor), and the constructed RCM. 


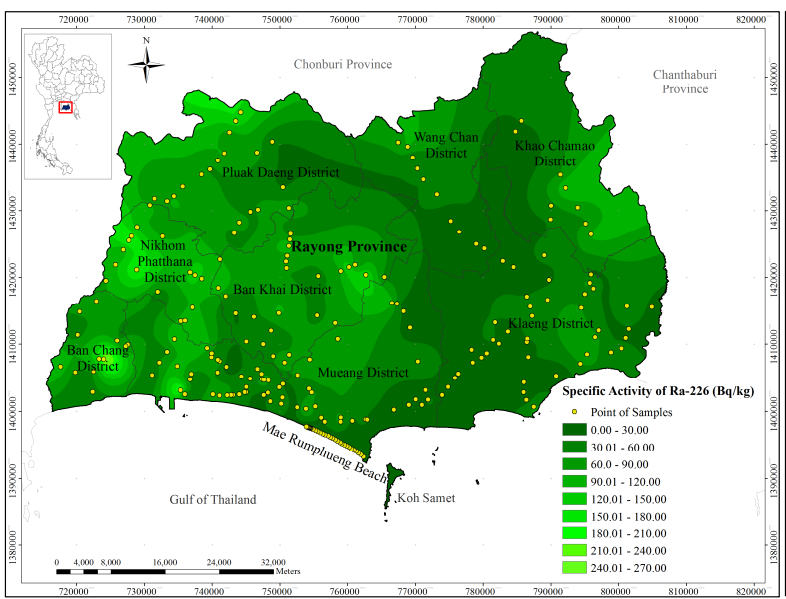

(a)

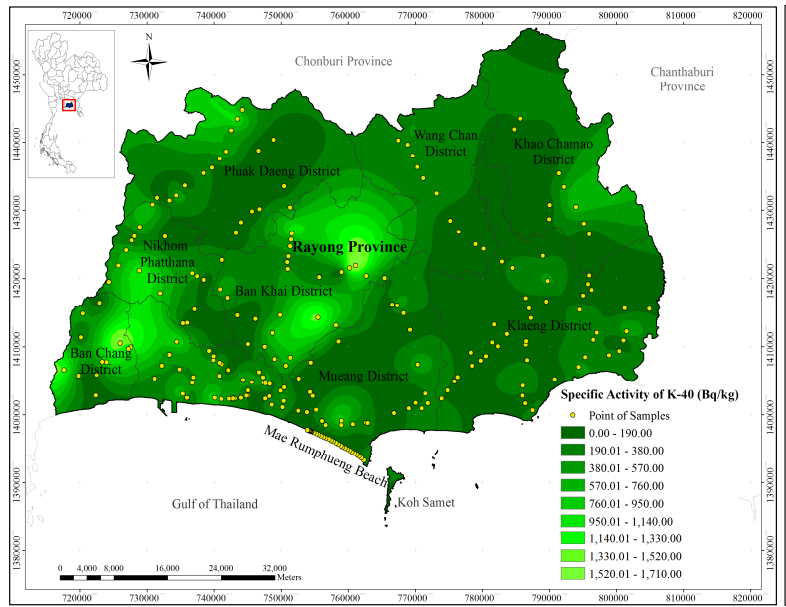

(c)

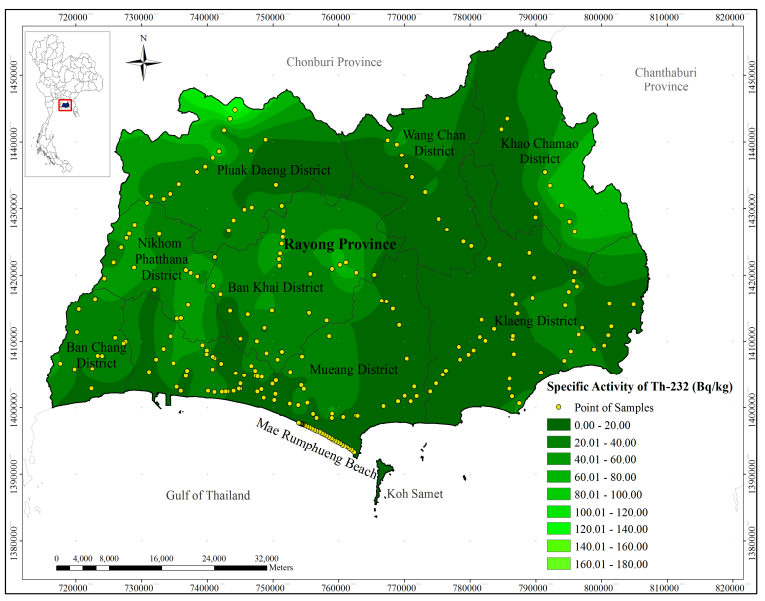

(b)

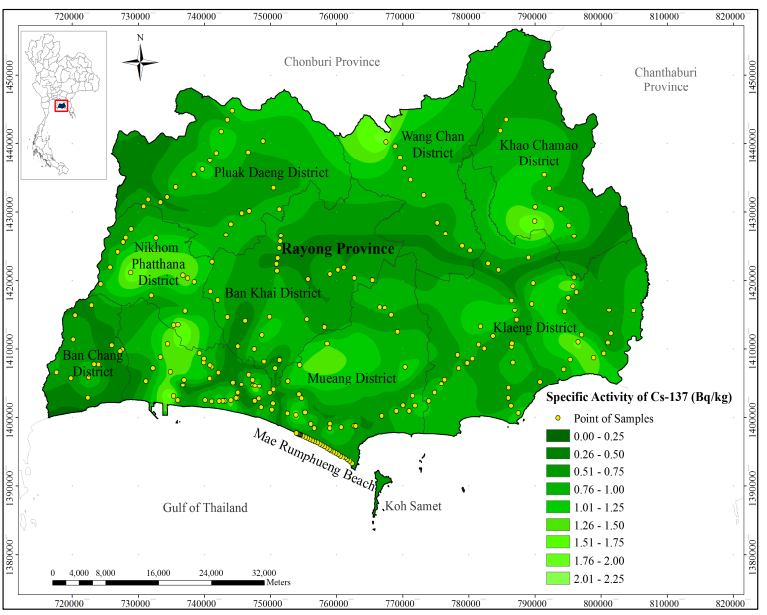

(d)

Fig. 4 RCM of: (a) ${ }^{226} \mathrm{Ra}$; (b) ${ }^{232} \mathrm{Th}$; (c) ${ }^{40} \mathrm{~K}$; and (d) ${ }^{137} \mathrm{Cs}$ in surface soil and beach sand samples in Rayong Province.

Most of the values obtained, except for the median value of ${ }^{226} \mathrm{Ra}$, were closed to or lower than previous national and international data, especially the OAP data and UNSCEAR recommended values. Moreover, all of the RCMs were in the same background radiation level. For this reason, the radioactive contaminants from the oil and gas extraction industry and human activities would not have a significant effect on surface soil and beach sand in Rayong Province. However, since the distribution of natural radionuclides $\left({ }^{226} \mathrm{Ra},{ }^{232} \mathrm{Th}\right.$, and $\left.{ }^{40} \mathrm{~K}\right)$ is the multimodal feature, the gamma emission activities in the studied area might be more or less mixed and accumulated. In addition, precaution has to be made from the finding that the median value of ${ }^{226} \mathrm{Ra}$, which is the highest concentration of natural radioactive material in the petroleum industry of the present study was higher than the UNSCEAR recommended value. This notification should require more attention and continuous monitoring during some routine operation in the studied area. For a beneficial aspect, all median values and associated calculations presented in this study can be used as a database to compare, monitor, and quantify possible changes in ecological radioactivity due to nuclear, accident, and other human activities in the future.

Acknowledgements: This work was supported by Research and Development Institute of Thaksin University and National Research Council of Thailand (Project No. 657667). We are grateful for facility support and technical cooperation provided by TINT. We are also impressed by the help from the Governor and administrative officers of Rayong Province during our sample collection period. The authors are particularly indebted to undergraduate and graduate students for their works and patience in sample collection, measurement, and analysis of the data. 


\section{REFERENCES}

1. Indhapanya C, Routray JK, Kammeier HD (1999) Spatial analysis of social impacts of the Eastern Seaboard Development Programme, Thailand. Impact Assess Proj Apprais 17, 203-216.

2. Thaipublica (2012) 30 Years of Eastern Seaboard Development Program (ESB), Bangkok, Thailand. Available at: https://thaipublica.org/2012/11/ 30-years-eastern-seaboard-development/. [in Thai]

3. Ministry of Industry (2002) Determination of Factory Type and Size, Establish Methods for Controlling Emissions of Waste, Pollution or any Matter Affecting the Environment, Define Moderator Qualifications Regular Worker and Registration Criteria for Supervisors for the Environmental Protection System for Toxicity, Ministry of Industry, Bangkok, Thailand. [in Thai]

4. Hamlat MS, Djeffal S, Kadi H (2001) Assessment of radiation exposures from naturally occurring radioactive materials in the oil and gas industry. Appl Radiat Isot 55, 141-146.

5. Ajayi TR, Torto N, Tchokossa P (2009) Natural radioactivity and trace metals in crude oils: implication for health. Environ Geochem Health 31, 61-69.

6. Bruzzi L, Baroni M, Mazzotti G, Mele R, Righi S (2000) Radioactivity in raw materials and end products in the Italian ceramics industry. $J$ Environ $R a$ dioact 47, 171-181.

7. Chang BU, Koh SM, Kim YJ, Seo JS, Yoon YY, Row JW, Lee DM (2008) Nationwide survey on the natural radionuclides in industrial raw minerals in South Korea. $J$ Environ Radioact 99, 455-460.

8. Iwaoka K, Tagami K, Yonehara H (2009) Measurement of natural radioactive nuclide concentrations in various metal ores used as industrial raw materials in Japan and estimation of dose received by workers handling them. J Environ Radioact 100, 993-997.

9. Afifi EM, Shahr El-Din AM, Aglan RF, Borai EH, Abo-Aly MM (2017) Baseline evaluation for natural radioactivity level and radiological hazardous parameters associated with processing of high grade monazite. Regul Toxicol Pharmacol 89, 215-223.

10. Iwaoka K, Yajima K, Suzuki T, Yonehara T, Hosoda M, Tokonami S, Kanda R (2017) Investigation of natural radioactivity in monazite processing plant in Japan. Health Phys 113, 220-224.

11. USGS (1999) Naturally Occurring Radioactive Materials (NORM) in Produced Water and Oil-field Equipment, An Issue for the Energy Industry USGS Fact Sheet FS-142-99, US Geological Survey, USA.

12. van Weers AW, Pace I, Strand T, Lysebo I, Watkins S, Sterker T, Meijne EIM, Butter KR (1997) Current Practice of Dealing with Natural Radioactivity from Oil and Gas Production in EU Member States, Rep. EUR 17621EN, Office for Official Publications of the European Communities, Luxembourg.

13. IAEA (2003) Radiation Protection and the Manage- ment of Radioactive Waste in the Oil and Gas, Industry Safety Reports Series No. 34, International Atomic Energy Agency, Vienna Austria.

14. Ahmed NK, Abbady A, El Arabi AM, Michel R, ElKamel AH, Abbady AGE (2006) Comparative study of the natural radioactivity of some selected rocks from Egypt and Germany. Indian J Pure Appl Phys 44, 209-215.

15. Tari M, Zarandi SAM, Mohammadi K, Zare MR (2013) The measurement of gamma-emitting radionuclides in beach sand cores of coastal regions of Ramsar, Iran using HPGe detectors. Mar Pollut Bull 74, 425-434.

16. Malain D, Regan PH, Bradley DA, Matthews M, AlSulaiti HA, Santawamaitre T (2012) An evaluation of the natural radioactivity in Andaman beach sand samples of Thailand after the 2004 tsunami. Appl Radiat Isot 70, 1467-1474.

17. Singh S, Rani A, Mahajan RK (2005) ${ }^{226} \mathrm{Ra},{ }^{232} \mathrm{Th}$ and ${ }^{40} \mathrm{~K}$ analysis in soil samples from some areas of Punjab and Himachal Pradesh, India using gamma ray spectrometry. Radiat Meas 39, 431-439.

18. UNSCEAR (2000) Sources and Effects of Ionizing Radiation, Report to General Assembly with Scientific Annexes, United Nations Scientific Committee on the Effects of Atomic Radiation, New York, USA.

19. Veiga R, Sanches N, dos Anjos RM, Macario K, Bastos J, Iguatemy M, Aguiar JG, Santos AMA, et al (2006) Measurement natural radioactivity in Brazilian beach sands. Radiat Meas 41, 189-196.

20. Beretka J, Mathew PJ (1985) Natural radioactivity of Australian building materials, industrial wastes and by-products. Health Phys 48, 87-95.

21. Qureshi AA, Tariq S, Ud Din K, Manzoor S, Calligaris C, Waheed A (2014) Evaluation of excessive lifetime cancer risk due to natural radioactivity in the rivers sediments of Northern Pakistan. J Radiat Res Appl Sci 7, 438-447.

22. TDRI (2019) What will Change when Thailand Became a Longevity Society?, TDRI Rep.152, Thailand Development Research Institute, Thailand. [In Thai]

23. UNSCEAR (1988) Sources and Effects of Ionizing Radiation, Report to General Assembly with Scientific Annexes, United Nations Scientific Committee on the Effects of Atomic Radiation, New York, USA.

24. UNSCEAR (1993) Sources and Effects of Ionizing Radiation, Report to General Assembly with Scientific Annexes, United Nations Scientific Committee on the Effects of Atomic Radiation, New York, USA.

25. Abedin MJ, Karim MR, Hossain S, Deb N, Kamal M, Miah MHA, Khandaker MU (2019) Spatial distribution of radionuclides in agricultural soil in the vicinity of a coal-fired brick kiln. Arab J Geosci 12, ID 236.

26. Ratanasumeniang C, Udomsomporn S, Benjakul S, Kessaratikoon P (2011) Measurement of specific activity of natural $\left({ }^{238} \mathrm{U},{ }^{232} \mathrm{Th},{ }^{226} \mathrm{Ra}\right.$ and $\left.{ }^{40} \mathrm{~K}\right)$ and anthropogenic $\left({ }^{137} \mathrm{Cs}\right)$ radionuclides in soil from 
Songkhla Province (Thailand). In: 20th Thaksin Univ Annual Conf: Thai Society Development with Creative Research, Songkhla, Thailand, pp 49-61.

27. Thongna $T$ (2009) Natural radioactivity assessment in Nakhon Si Thammarat Province. MS thesis, Thaksin Univ, Thailand.

28. Daoh M (2010) Measurement of specific activity of natural $\left({ }^{40} \mathrm{~K},{ }^{226} \mathrm{Ra}\right.$ and $\left.{ }^{232} \mathrm{Th}\right)$ and anthropogenic radionuclides $\left({ }^{137} \mathrm{Cs}\right)$ in soil from Phathalung Province (Thailand) using gamma ray spectrometry. MS thesis, Thaksin Univ, Thailand.

29. Chauymanee S (2012) Assessment of natural and anthropogenic radioactivity in soil and beach sand samples in Chumphon Province. MS thesis, Thaksin Univ, Thailand.

30. Kessaratikoon P, Boonkrongcheep R, Benjakul S, Youngchauy U (2013) Assessment and radioactive contour maps of specific activities of natural $\left({ }^{40} \mathrm{~K}\right.$, ${ }^{226} \mathrm{Ra}$ and $\left.{ }^{232} \mathrm{Th}\right)$ and anthropogenic $\left({ }^{137} \mathrm{Cs}\right)$ radionuclides in surface soil samples from Surat Thani Province, Thailand. In: 8th Annual Conf of the Thai Physics Society (SPC 2013): Thai Physics Society on the Road to ASEAN Community, Chiang Mai, Thailand.

31. Kessaratikoon P, Kuaket B, Wongjan B, Suakaew P, Boonkrongcheep R (2018) Investigation of natural radioactivity and radiological hazard assessment in surface soil samples from Ranong Province (Thailand). In: 42nd Congress on Science and Technology of Thailand (STT42): Knowledge of the Land towards Innovation for Sustainable Future, Bangkok, Thailand, pp 47-53.

32. Kessaratikoon P, Boonkrongcheep R, Benjakul S, Udomsomporn $S$ (2014) Measurement of specific activity of natural radionuclides $\left({ }^{40} \mathrm{~K},{ }^{226} \mathrm{Ra}\right.$ and $\left.{ }^{232} \mathrm{Th}\right)$, radiological hazard assessment and radioactive contour maps in surface soil samples collected from Trang Province, Thailand. In: 9th Annual Conf of the Thai Physics Society (SPC 2014): High Speed Physics, Nakhon Ratchasima, Thailand.

33. Kessaratikoon P, Boonkrongcheep R, Benjakul S, Meena M, Udomsomporn S (2015) Radiological hazard assessment and radioactive contour maps in surface soil samples collected from Satun Province, Thailand. In: 10th Annual Siam Physics Congress
2015 (SPC 2015): The Centennial Celebration of General Relativity Theory and 80 Years of Thai Physics Graduate, Krabi, Thailand, pp 201-210.

34. Jahlee M (2012) Quantitative measurement of natural $\left({ }^{40} \mathrm{~K},{ }^{226} \mathrm{Ra}\right.$ and $\left.{ }^{232} \mathrm{Th}\right)$ and anthropogenic radionuclides $\left({ }^{137} \mathrm{Cs}\right)$ in soil samples from Yala Province, Thailand. MS thesis, Thaksin Univ, Thailand.

35. Kessaratikoon P, Boonkrongcheep R, Benjakul S, Youngchauy U (2015) Measurement of specific activity of natural and anthropogenic radionuclides and radiological hazard assessment in surface soil samples collected from three provinces (Phuket, Phang Nga and Krabi) along the Andaman sea coast in southern region of Thailand. J Phys Conf Ser 611, $1-8$.

36. Njinga RL, Tshivhase VM (2016) Lifetime cancer risk due to gamma radioactivity in soils from Tudor Shaft mine environs, South Africa. J Radiat Res Appl Sci 9, 310-315.

37. Gbadamosi MR, Banjoko OO, Abudu KA, Ogunbanjo OO, Ogunneye AL (2017) Radiometric evaluation of excessive lifetime cancer probability due to naturally occurring radionuclides in wastes dumpsites soils in Agbara, Southwest, Nigeria. J Assoc Arab Univ Basic Appl Sci 24, 1-10.

38. Al-Ghamdi AH (2019) Health risk assessment of natural background radiation in the soil of Eastern province, Saudi Arabia. J Radiat Res Appl Sci 12, 219-225.

39. Amanjeet, Kumar A, Kumar S, Singh J, Singh P, Bajwa BS (2017) Assessment of natural radioactivity levels and associated dose rates in soil samples from historical city Panipat, India. J Radiat Res Appl Sci 10, 283-288.

40. Liua X, Linb W (2018) Natural radioactivity in the beach sand and soil along the coastline of Guangxi Province, China. Mar Pollut Bull 135, 446-450.

41. OAP (2002) OAP 1994-2002 Annual Reports, Office of Atoms for Peace, Bangkok, Thailand.

42. Hilal MA, Attallah MF, Mohamed GY, Fayez-Hassan M (2014) Evaluation of radiation hazard potential of TENORM waste from oil and natural gas production. J Environ Radioact 136, 121-126. 